\title{
Coulomb Complexing and the Solubilization of Oxides in Halide Melts
}

\author{
M. Blander and Z. Nagy \\ Argonne National Laboratory Argonne, Illinois, USA \\ Z. Naturforsch. 38 a, 116-119 (1983); received September 27, 1982 \\ Dedicated to Professor Alfred Klemm on the occasion of his 70th birthday
}

\begin{abstract}
Coulomb attractions between polyvalent cations and anions in alkali halide melts lead to the formation of complex ions and to the solubilization of oxides of some cations by their halides. We have observed such solubilizations of $\mathrm{Al}_{2} \mathrm{O}_{3}$ in $\mathrm{LiCl}-\mathrm{KCl}$ eutectic melts. In addition, we predict and observe the dissolution of a number of other oxides by $\mathrm{AlCl}_{3}$ in $\mathrm{LiCl}-\mathrm{KCl}$ melts. We also predict that solubilization will be better in other halide solvents. Our results suggest possible new media for pyrometallurgy and chemical and electrochemical processes.
\end{abstract}

We have observed the solubilization of $\mathrm{Al}_{2} \mathrm{~S}_{3}$ and $\mathrm{Al}_{2} \mathrm{O}_{3}$ by $\mathrm{AlCl}_{3}$ in $\mathrm{LiCl}-\mathrm{KCl}$ eutectic melts [1-3]. Such solubilization occurs because of the formation of complex species such as $\mathrm{AlS}^{+}$, and perhaps $\mathrm{AlO}^{+}$, in which a major part of the binding stems from the coulomb attraction between the polyvalent ions $\mathrm{Al}^{+3}$ and $\mathrm{S}^{-2}$ or $\mathrm{O}^{-2}$. Such coulomb complexing is an important concept which should be significant in the solubilization of many other polyvalent oxides by their own halides in melts such as alkali halides. A large number of oxides (and possibly sulfides) can be solubilized by their own halides or by other halides of metals (such as $\mathrm{AlCl}_{3}$ ) which solubilize their own oxide. A simple analysis of the phenomenon leads to predictions concerning the best solvents for strong coulomb complexing [1, 2]. This phenomenon should be significant in pyrometallurgy and in chemical and electrochemical processing as it makes possible a range of new solvents for oxides and sulfides.

In this communication we will discuss our work on oxide solubilization. First, we will discuss the concept of coulomb complexing and its consequences. Following that, we will present our preliminary experiments to test our predictions in the $\mathrm{LiCl}-\mathrm{KCl}$ eutectic melt. As we shall see, our experiments confirm the prediction that a number of oxides are completely solubilized by $\mathrm{AlCl}_{3}$ in the $\mathrm{LiCl}-\mathrm{KCl}$ melt. According to the concepts we discuss, solvents other than $\mathrm{LiCl}-\mathrm{KCl}$ should perform this solubilization much better.

Reprint requests to Prof. Dr. M. Blander, Chemical Technology Division, Argonne National Laboratory, Argonne, Illinois 60439, USA.

\section{Coulomb Complexing}

We define a coulomb complex as a species in which most of the energy of "bond" formation arises from the classical electrostatic attractions between oppositely charged ions. For example, when an $\mathrm{Al}^{+3}$ ion is dissolved in an alkali halide, the trivalent $\mathrm{Al}^{+3}$ ion replaces a monovalent alkali ion with a net charge of +2 . Similarly a divalent $\mathrm{O}^{-2}$ ion replaces a monovalent halide ion with a net charge of -1 . Consequently, if there were no shielding by the solvent ions, there should be a large coulomb attraction between the $\mathrm{Al}^{+3}$ and $\mathrm{O}^{-2}$ ions. If the interionic pair potential is given by $\left(A / r^{n}+Z_{\mathrm{a}} Z_{\mathrm{c}} e^{2} / r\right)$ where $A$ is a constant dependent on the sum of the ionic radii, $r$ is the distance between the ions, $e$ is the charge on the electron, and $Z_{\mathrm{a}}$ and $Z_{\mathrm{c}}$ are the anion and cation net charges, then the energy for forming an $\mathrm{AlO}^{+}$or $\mathrm{AlS}^{+}$species from separated $\mathrm{Al}^{+3}$ and $\mathrm{X}^{-2}$ ions would be approximately $-2 e^{2}(n-1) / n d$ where $d$ is the sum of the radii of the $\mathrm{Al}^{+3}$ and $\mathrm{X}^{-2}$ ions. If we choose a typical value of $n=9$ and we use the Pauling radii to calculate $d$, then the energy for forming an $\mathrm{AlO}^{+}$ species is about $-1.29 \mathrm{MJ} / \mathrm{mole}$ and for an $\mathrm{AlS}^{+}$ species it is about $-1.05 \mathrm{MJ} / \mathrm{mole}$.

Using a statistical mechanical expression [4] for the formation constant, $K$, in terms of the energy of formation, $\Delta E$ :

$$
K=Z[\exp (-\Delta E / R T)-1],
$$

the above energies (for values of $Z=4-6$ ) would lead to a value of $K$ of about $10^{94}$ for the $\mathrm{AlO}^{+}$ species and about $10^{76}$ for the $\mathrm{AlS}^{+}$species at $723 \mathrm{~K}$ (for the reaction: $\mathrm{Al}^{+3}+\mathrm{X}^{-2} \rightleftharpoons \mathrm{AlX}^{+}$). These values 
of $K$ are very much larger than our preliminary measured value of $10^{29}$ for the $\mathrm{AlO}^{+}$species and a value of less than $10^{12}$ for the $\mathrm{AlS}^{+}$species in the $\mathrm{LiCl}-\mathrm{KCl}$ eutectic $[1-3]$. Obviously there is a considerable degree of screening, probably of the $\mathrm{O}^{-2}$ and $\mathrm{S}^{-2}$ ions by the small $\mathrm{Li}^{+}$cations. Screening is more effective with the large sulfide ion than with the smaller oxide ion and reduces the energy more than $85 \%(\Delta E>-0.16 \mathrm{MJ} / \mathrm{mole})$ for the $\mathrm{AlS}^{+}$species as compared to about $70 \%(\Delta E=-0.39 \mathrm{MJ} / \mathrm{mole})$ for the $\mathrm{AlO}^{+}$species. One would predict that such screening would decrease, and the formation constants increase, if one increases the radius of the smallest alkali cation in the melt. An analogous but probably smaller effect will occur with an increase of the radius of the halide ion.

When the only complex is $\mathrm{AlX}^{+}$then the solubilization of oxides is governed not only by the formation constant, $K$, but also by the solubility product, $K_{\text {sp }}$. The concentration of the $\mathrm{AlX}^{+}$ion (and hence of $\mathrm{Al}_{2} \mathrm{X}_{3}$ ) in the Henry's law region is governed by the relation

$$
x_{\mathrm{AlX}^{+}}=K\left(K_{\mathrm{sp}} x_{\mathrm{Al}^{+3}}\right)^{1 / 3} .
$$

Thus, in deducing solubilization one must consider the solvent dependence not only of $K$ but also of $K_{\text {sp. }}$. As has been shown $[1,5,6]$, solubility products can often be predicted a priori based on independent data and theoretical considerations.

Coulomb complexing of oxide ions should be significant with other polyvalent cations. For example, if we increase the radius of the trivalent cation from that of $\mathrm{Al}^{+3}$ to $\mathrm{Y}^{+3}$ and to $\mathrm{La}^{+3}$ (with Pauling radii of $0.50,0.93$, and $1.15 \AA$, respectively), the energy of coulomb complexing will become less negative and $K$ will decrease. However, if coulomb interactions make important contributions to the lattice energy of the solid, it is likely that the $K_{\mathrm{sp}}$ will increase with an increase of radius to that solubilization could occur if there is compensation for the decrease in $K$ in (2). All other factors being equal, coulomb complexing will increase with cationic charge so that, e.g. tetravalent ions such as $\mathrm{Ti}^{+4}$ and $\mathrm{Zr}^{+4}$ should form relatively strong bonds and divalent ions such as $\mathrm{Mg}^{+2}$ and $\mathrm{Ca}^{+2}$ should form relatively weak bonds.

In addition to the possibility of oxides other than $\mathrm{Al}_{2} \mathrm{O}_{3}$ being solubilized by halides of the same metal, one should be able to solubilize oxides which react with $\mathrm{AlCl}_{3}$ in solution to form a halide by a reaction such as:

$$
\begin{aligned}
& (1 / 2 n) \mathrm{MO}_{n} \text { (solid) }+(1 / 3) \mathrm{AlCl}_{3} \text { (soln) } \\
& \quad \rightarrow(1 / 6) \mathrm{Al}_{2} \mathrm{O}_{3} \text { (solid) }+(1 / 2 n) \mathrm{MCl}_{2 n} \text { (soln) } .
\end{aligned}
$$

If $\mathrm{AlO}^{+}$is the only complex species then with an excess of $\mathrm{AlCl}_{3}$ the total reaction will be

$$
\begin{aligned}
& \mathrm{MO}_{n}(\text { solid })+n-\mathrm{AlCl}_{3}(\text { soln }) \\
& \quad \rightarrow \mathrm{MCl}_{2 n}(\text { soln })+n-\mathrm{AlOCl}(\text { soln }),
\end{aligned}
$$

where both products of the reaction are soluble. (Analogous reactions should occur with other metal halides if they solubilize their own oxides.) There will be an enhancement in the solubilization of $\mathrm{MO}_{n}$ (solid) by $\mathrm{AlCl}_{3}$ it the $\mathrm{M}^{+2 n}$ ion itself complexes oxide ions. This will result in the need for smaller amounts of $\mathrm{AlCl}_{3}$ to solubilize an oxide than would be calculated based on Eqs. (3) and (4). The presence of $\mathrm{Al}^{+3}$ and $\mathrm{O}^{-2}$ containing complex ions other than $\mathrm{AlO}^{+}$may alter our specific conclusions i.e. that reaction (4) will be predominant but will not negate our general conclusions that a large number of oxides will be solubilized by a combination of reaction (3) and those reactions responsible for the observed solubilization of $\mathrm{Al}_{2} \mathrm{O}_{3}$. A measure of the ability of $\mathrm{AlCl}_{3}$ solutions to solubilize oxides is the standard free energy change for reaction (3). Data were available to calculate these quantities for a number of oxides in the $\mathrm{LiCl}-\mathrm{KCl}$ eutectic at $450{ }^{\circ} \mathrm{C}[7-9]$. These are given in Table 1 . Of course this table is not exhaustive and many oxides for which no data are available should also react to go

\begin{tabular}{|c|c|c|c|c|c|}
\hline $\begin{array}{l}\text { Oxide } \\
(n=1)\end{array}$ & $\Delta G^{0}$ & $\begin{array}{l}\text { Oxide } \\
(n=1.5)\end{array}$ & $\Delta G^{0}$ & $\begin{array}{l}\text { Oxide } \\
(n=2)\end{array}$ & $\Delta G^{0}$ \\
\hline $\begin{array}{l}\mathrm{BeO} \\
\mathrm{CoO} \\
\mathrm{CuO} \\
\mathrm{FeO} \\
\mathrm{MgO} \\
\mathrm{MnO} \\
\mathrm{NiO} \\
\mathrm{PbO} \\
\mathrm{TiO} \\
\mathrm{VO} \\
\mathrm{ZnO}\end{array}$ & $\begin{array}{l}+4 \\
-73 \\
-88 \\
-72 \\
-55 \\
-80 \\
-58 \\
-100 \\
+0.3 \\
-33 \\
-80\end{array}$ & $\begin{array}{l}\mathrm{Bi}_{2} \mathrm{O}_{3} \\
\mathrm{Ce}_{2} \mathrm{O}_{3} \\
\mathrm{Cr}_{2} \mathrm{O}_{3} \\
\mathrm{Fe}_{2} \mathrm{O}_{3} \\
\mathrm{Ga}_{2} \mathrm{O}_{3} \\
\mathrm{Gd}_{2} \mathrm{O}_{3} \\
\mathrm{La}_{2} \mathrm{O}_{3} \\
\mathrm{Nd}_{2} \mathrm{O}_{3} \\
\mathrm{Ti}_{2} \mathrm{O}_{3} \\
\mathrm{~V}_{2} \mathrm{O}_{3} \\
\mathrm{Y}_{2} \mathrm{O}_{3}\end{array}$ & $\begin{array}{l}-89 \\
-87 \\
-23 \\
-39 \\
-38 \\
-72 \\
-82 \\
-76 \\
-7 \\
-22 \\
-62\end{array}$ & $\begin{array}{l}\mathrm{GeO}_{2} \\
\mathrm{HfO}_{2} \\
\mathrm{SnO}_{2} \\
\mathrm{ThO}_{2} \\
\mathrm{TiO}_{2} \\
\mathrm{UO}_{2} \\
\mathrm{ZrO}_{2}\end{array}$ & $\begin{array}{l}-38 \\
+\quad 3 \\
-32 \\
-28 \\
-13 \\
-7 \\
-21\end{array}$ \\
\hline
\end{tabular}

Table 1. Standard Free Energy Change for the Reaction $(1 / 2 n) \mathrm{MO}_{n}$ (solid) $+(1 / 3) \mathrm{AlCl}_{3}($ soln $) \rightarrow(1 / 6) \mathrm{Al}_{2} \mathrm{O}_{3}$ (solid) $+(1 / 2 n) \mathrm{MCl}_{2 n}$ (soln) in the $\mathrm{LiCl}-\mathrm{KCl}$ Eutectic Mixture at $450^{\circ} \mathrm{C}(\mathrm{kJ} / \mathrm{mole})$. 
into solution. All of the oxides of the listed metals except $\mathrm{HfO}_{2}$ should dissolve. Oxides of monovalent or divalent cations for which $\Delta G^{0}$ is somewhat positive (i.e. $\mathrm{BeO}$ and $\mathrm{TiO}$ ) should dissolve to a significant degree whereas oxides of tetravalent cations should not dissolve significantly unless $\Delta G^{0}$ is somewhat negative. If the $\mathrm{M}^{+2 n}$ ions themselves complex oxide ions or, there could be a disproportionation reaction (e.g., for $\mathrm{Ti}^{+3}$ or $\mathrm{U}^{+4}$ ) the solubilities would be enhanced.

\section{Measurement of Solubilization}

In this section we discuss tests of our predictions on the solubilization of metal oxides and will also show that oxides other than those in Table 1 will dissolve in an $\mathrm{LiCl}-\mathrm{KCl}$ eutectic melt $(58 \mathrm{~mole} \%$ $\mathrm{LiCl}-42 \mathrm{Mole} \% \mathrm{KCl}$ ) containing $\mathrm{AlCl}_{3}$.

The experiments were carried out in a helium filled glovebox with a furnace well attached to the bottom of the box. The well was surrounded and heated by a wire wound furnace. The glovebox atmosphere was continuously circulated through a purifier, and the oxygen and water content were kept below $5 \mathrm{ppm}$. The melt was contained in long, fused-silica test tubes reaching through the full length of the open furnace well; each tube also contained a fused-silica rod for occasional manual stirring. Usually six of the tubes were inserted into the well simultaneously.

All chemicals were high purity grade and completely dry. Polarographic grade $\mathrm{LiCl}-\mathrm{KCl}$ eutectic and $\mathrm{KAlCl}_{4}$ were obtained from Anderson Physics Laboratory, Inc. (Urbana, IL). Chloroluminate was used instead of $\mathrm{AlCl}_{3}$, because of its availability in high purity form as relatively large crystals formed from a melt. All the above materials were supplied sealed in glass ampules under inert atmosphere, and were used without any further purification. All oxides were vacuum dried at $250^{\circ} \mathrm{C}$.

An experiment was typically carried out as follows. Approximately $8 \mathrm{~g}$ of the eutectic was melted in the tubes to give a molten salt column of about $4 \mathrm{~cm}$ high. The oxides were added and the tubes were left in the well over-night to check any initial solubility; the chloride complexing agent was then added. The concentration was typically one mole $\%$ metal chloride, and enough oxide to result in an oxygen to complexing metal mole ratio of about 0.1 . The appearance of the melts could be observed by lifting the tube from the furnace well and inspecting it under a bright light. There was about a half a minute time available for observation, before the melt started to solidify. The melts were occasionally stirred manually. The temperature of the melts was not directly measured and was probably somewhat below the $500^{\circ} \mathrm{C}$ well temperature. Although dissolution would probably be faster at higher temperatures, the use of open tubes precluded raising temperatures in order to minimize volatilization of $\mathrm{AlCl}_{3}$ (probably as $\mathrm{KAlCl}_{4}$ ).

The following oxides were tested with $\mathrm{KAlCl}_{4}$ : $\mathrm{CoO}, \mathrm{Cr}_{2} \mathrm{O}_{3}, \mathrm{Dy}_{2} \mathrm{O}_{3}, \mathrm{Eu}_{2} \mathrm{O}_{3}, \mathrm{La}_{2} \mathrm{O}_{3}, \mathrm{MgO}, \mathrm{MnO}_{2}$, $\mathrm{NiO}, \mathrm{SiO}_{2}, \mathrm{TiO}_{2}, \mathrm{ThO}_{2}, \mathrm{UO}_{2}, \mathrm{Y}_{2} \mathrm{O}_{3}$, and $\mathrm{ZrO}_{2}$. Of these fourteen, four are not listed in Table $1\left(\mathrm{Dy}_{2} \mathrm{O}_{3}\right.$, $\mathrm{Eu}_{2} \mathrm{O}_{3}, \mathrm{MnO}_{2}$ and $\mathrm{SiO}_{2}$ ).

Practically no dissolution of the oxides was observed before the addition of the complexing halides as judged by the amount of visible powder in the test tubes (or the faintness of color in solution). After the addition of the complexing agent, the oxides typically started to dissolve immediately as indicated by a diminution in the oxide powder present and sometimes by the appearance of color. Usually, there were some particles left undissolved for a long time after the addition of $\mathrm{KAlCl}_{4}$ to the melt; in some cases 3-4 days were needed to dissolve all the oxide. All tests resulted in practically complete dissolution of the oxides by the $\mathrm{AlCl}_{3}$ containing melts.

The following oxides exhibited colored melts: $\mathrm{Eu}_{2} \mathrm{O}_{3}$ and $\mathrm{MnO}_{2}$ gave light yellow melts while $\mathrm{NiO}$ resulted in dark blue melts. These melts were colorless before the addition of the complexing agent. There was some initial color with $\mathrm{CoO}$ (light blue) and $\mathrm{UO}_{2}$ (light yellow) which turned into dark blue and brown-orange, respectively, after the addition of the chloride.

It should be made clear that these results are preliminary. Because of the difficulties in observing the small amounts of oxides involved in these measurements confirmation of our results will be made using more quantitative techniques.

An additional experiment was carried out with $\mathrm{UO}_{2}$ at an $\mathrm{O} / \mathrm{Al}$ mole ratio of 0.9 with an $\mathrm{AlCl}_{3}$ concentration of $0.96 \mathrm{~mole} \%$. In this case, the melt was chemically analyzed for uranium, before and after the addition of $\mathrm{KAlCl}_{4}$. The analysis indicated that approximately $80 \%$ of the $\mathrm{UO}_{2}$ dissolved; the concentration increased from the initial value of 
$0.009 \mathrm{~mole} \%$ to $0.33 \mathrm{~mole} \%$. At the same time, a white precipitate (presumably $\mathrm{Al}_{2} \mathrm{O}_{3}$ ) was formed. If the thermodynamic data are correct, the reaction did not go to completion, possibly because of a tendency for the $\mathrm{Al}_{2} \mathrm{O}_{3}$ product to coat the $\mathrm{UO}_{2}$ which could slow the dissolution considerably or because some of the $\mathrm{AlCl}_{3}$ volatilized. At any rate, these preliminary measurements are consistent with our predictions of significant solubilization of $\mathrm{UO}_{2}$ (even while keeping the $\mathrm{Al}_{2} \mathrm{O}_{3}$ in solution if an excess of $\mathrm{AlCl}_{3}$ is used).

\section{Discussion}

We have illustrated some of our predictions.

1. Coulomb complexing leads to strong bonding of polyvalent ions with oxide ions. As a consequence, polyvalent halides may complex oxides of the same metal strongly enough to solubilize them. We have demonstrated this for $\mathrm{Al}^{+3}$.

2. Such solubilizing halides will also solubilize many other oxides for which reactions analogous to reaction (3) have a favorable standard free energy change. This was demonstrated for $\mathrm{Al}^{+3}$ ions with the oxides of $\mathrm{Co}, \mathrm{Cr}(\mathrm{III}), \mathrm{La}, \mathrm{Mg}, \mathrm{Ni}, \mathrm{Ti}(\mathrm{IV}), \mathrm{Th}$, $\mathrm{U}(\mathrm{IV}), \mathrm{Y}$, and $\mathrm{Zr}$.

3. Other reactions such as disproportionation or coulomb complexing of the solubilized cations could enhance the solubilization of oxides.

Four of the oxides which were solubilized, $\mathrm{Dy}_{2} \mathrm{O}_{3}$, $\mathrm{Eu}_{2} \mathrm{O}_{3}, \mathrm{MnO}_{2}$, and $\mathrm{SiO}_{2}$ are not listed in Table 1. Of these, $\mathrm{Dy}_{2} \mathrm{O}_{3}$ and $\mathrm{Eu}_{2} \mathrm{O}_{3}$ should be similar to the other rare earths in Table 1 and would be expected to dissolve in our melts. For $\mathrm{MnO}_{2}$ there was insuf-

[1] Z. Nagy, J. L. Settle, J. Padova, and M. Blander, Abstract 34, p. 93, The Electrochemical Society Extended Abstracts, St. Louis, Missouri, May 11-16, 1980.

[2] Z. Nagy, J. L. Settle, J. Padova, and M. Blander, J. Electrochem. Soc. 129, 2034 (1982).

[3] Z. Nagy, J. L. Settle, and M. Blander, unpublished results.

[4] M. Blander, J. Chem. Phys. 34, 432 (1961).

[5] M.-L. Saboungi, J. J. Marr, and M. Blander, J. Electrochem. Soc. 125, 1567 (1978).

[6] M.-L. Saboungi, J. J. Marr, and M. Blander, Met. Trans. B 10, 477 (1979). ficient data to make predictions. For $\mathrm{SiO}_{2}$, our calculations based on Eqs. (3) and (4) indicated that essentially no solubilization (or even volatilization of $\mathrm{SiCl}_{4}$ ) should have occured. (The calculated partial pressure of $\mathrm{SiCl}_{4}$ vapor is very small $\left(<10^{-6} \mathrm{~atm}\right)$ and the activity of $\mathrm{SiCl}_{4}$ in solution (liquid as standard state) is smaller than $10^{-8}$.) Our fused-silica tubes were only slightly etched. Our observation of the solubilization of fine $\mathrm{SiO}_{2}$ powder, if true, indicates that kinetic factors are important and that, if the thermodynamic data are correct, reactions other than (3) and (4) must be significant. One obvious possibility is the reaction

$$
\mathrm{SiO}_{2}+\mathrm{AlCl}_{3} \rightarrow \mathrm{SiOCl}_{2}+\mathrm{AlOCl}
$$

where the $\mathrm{SiO}^{+2}$ complex is very stable.

Our results have implications relevant to technology and suggest possible new media for pyrometallurgy, and chemical and electrochemical processes. We are planning more quantitative measurements in the $\mathrm{LiCl}-\mathrm{KCl}$ eutectic and will examine other molten salt solvents in which we predict even larger complexation of oxides and sulfides. We will also examine complexation in more detail as there is a distinct possibility that reactions other than those we postulate could be important.

\section{Acknowledgements}

We are grateful to T. J. Gerding and A. M. Essling for their help with the experiments with $\mathrm{UO}_{2}$ and to T. Østvold for considerable help and advice. This work was performed under the auspices of the Division of Materials Science, Office of Basic Energy Sciences, U.S. Department of Energy.

[7] J. A. Plambeck, Encyclopedia of Electrochemistry of the Elements, Vol. 10, p. 68, A. J. Bard, Editor, Marcel Dekker, New York 1976.

[8] D. R. Stull and H. Prophet, JANAF Thermochemical Tables, 2nd ed., National Bureau of Standards, NSRDS-NBS-37, Washington 1971.

[9] R. A. Robie, B. S. Hemingway, and J. R. Fisher, Thermodynamic Properties of Minerals and Related Substances, Geological Survey Bulletin 1452, U.S. Gov't. Printing Office, Washington 1978. 